\title{
Co-incidence of Human
} Papillomaviruses and Epstein-Barr Virus Is Associated With High to Intermediate Tumor Grade in Human Head and Neck Cancer in Syria

\author{
Ishita Gupta ${ }^{1,2 t}$, Lina Ghabreau ${ }^{3,4 \dagger}$, Hamda Al-Thawadi ${ }^{1}$, Amber Yasmeen ${ }^{5}$, Semir Vranic ${ }^{1}$, \\ Ala-Eddin Al Moustafa ${ }^{1,2 \star}$ and Mohammed I. Malki ${ }^{1}$ \\ ${ }^{1}$ College of Medicine, QU Health, Qatar University, Doha, Qatar, ${ }^{2}$ Biomedical Research Centre, Qatar University, Doha, Qatar, \\ ${ }^{3}$ Pathology Department, Faculty of Medicine, University of Aleppo, Aleppo, Syria, ${ }^{4}$ Syrian Research Cancer Centre of the \\ Syrian Society Against Cancer, Aleppo, Syria, ${ }^{5}$ Segal Cancer Centre, Lady Davis Institute for Medical Research of the Sir \\ Mortimer B. Davis-Jewish General Hospital, Montreal, QC, Canada
}

OPEN ACCESS

Edited by:

Stéphane Hans,

Hôpital Foch, France

Reviewed by:

Stefania Staibano,

University of Naples Federico II, Italy

Gaurisankar Sa,

Bose Institute, India

*Correspondence:

Ala-Eddin Al Moustafa

aalmoustafa@qu.edu.qa

†These authors have contributed equally to this work

Specialty section

This article was submitted to

Head and Neck Cancer,

a section of the journal

Frontiers in Oncology

Received: 06 January 2020

Accepted: 22 May 2020

Published: 20 August 2020

Citation:

Gupta I, Ghabreau L, Al-Thawadi H,

Yasmeen A, Vranic S, Al Moustafa A-E and Malki MI (2020) Co-incidence of

Human Papillomaviruses and

Epstein-Barr Virus Is Associated With

High to Intermediate Tumor Grade in

Human Head and Neck Cancer in

Syria. Front. Oncol. 10:1016.

doi: 10.3389/fonc.2020.01016
High-risk human papillomaviruses (high-risk HPVs) have been recently reported to be co-present with Epstein-Barr virus (EBV) in different types of human cancers including head and neck $(\mathrm{HN})$, where they can cooperate in the initiation and/or progression of this cancer. Accordingly, we herein explored the prevalence of high-risk HPVs and EBV in $80 \mathrm{HN}$ cancer tissues from the Syrian population using polymerase chain reaction, immunohistochemistry, and tissue microarray methodologies. We report that high-risk HPVs and EBV are present in 35/80 (43.7\%) and 41/80 (51.2\%) of our samples, respectively, and the most frequent HPV types are 33, 16, 18, 45, 52, 58, 35,51 , and 31 , in this order. More significantly, our data reveal that 25/80 (31.2\%) of cancer cases are positive for high-risk HPVs as well as EBV, and their co-presence is associated with high/intermediate-grade squamous cell carcinomas. These data confirm the co-presence of high-risk HPVs and EBV in HN cancers in the Syrian population of the Middle East and demonstrate that their co-incidence is linked to a more aggressive cancer phenotype. Thus, future studies are required to confirm these data and elucidate the exact role of high-risk and EBV cooperation in human HN carcinogenesis.

Keywords: head and neck cancers, human papillomaviruses, Epstein-Barr virus, tumor grade, Syrian population

\section{INTRODUCTION}

Head and neck $(\mathrm{HN})$ cancer is a broad term that incorporates epithelial malignancies located in the paranasal sinuses, oral cavity, nasal cavity, pharynx, and larynx (1). HN cancer is one of the most common among both male and female worldwide, with around 650,000 new cases and 330,000 deaths each year assessed by the World Health Organization (2); notably, most of these deaths occur in developing countries (3). When it comes to cancer-related mortality, it is generally either directly attributed to metastasis, as in tumor involvement of critical organs, or caused indirectly due to therapeutic resistance and the adverse effect of treatment on human organs $(4,5)$.

Today, it is well-known that more than $20 \%$ of human cancers are estimated to be linked with microorganism infections including oncoviruses infection especially high-risk human 
papillomaviruses (high-risk HPV) and Epstein-Barr virus (EBV) (6-8). More specifically, it has been well-established that highrisk HPV infections are critical etiological factors in the development of human HN cancers, especially oral, as $\sim 40 \%$ of oral cancer cases are positive for high-risk HPVs, particularly types $16,18,31,33,35,45,52$, and 58 worldwide including the Middle East (ME) region $(7,9)$. Additionally, it was pointed out that their presence is linked with vascular invasion and lymph node metastases in different types of human carcinomas including cervical and HN (10-12).

Likewise, EBV is a human gamma herpesvirus that commonly infects more than $90 \%$ of the adult population (13). Persistent infection with EBV can cause infectious mononucleosis, and its latent state can lead to several types of human B-cell lymphomas and certain solid cancers, especially nasopharyngeal (14-17); additionally, EBV has been shown to be strongly associated with undifferentiated nasopharyngeal carcinomas (NPCs). Several studies have detected the presence of $\mathrm{EBV}$ in $\mathrm{HN}$ squamous cell tumors implying its possible role in the development of malignancies throughout the upper aerodigestive tract $(7,18,19)$. Moreover, it has been recently revealed that EBNA1 and LMP1 of EBV oncoproteins can enhance invasion of human cancer cells via the induction of epithelial-to-mesenchymal transition (EMT) $(20,21)$.

On the other hand, several recent studies revealed that highrisk HPVs and EBV are co-present in human HN cancers especially oral (22-24). Moreover, it has been reported that the co-occurrence of high-risk HPVs and EBV in oral cancer is associated with a significant increase in the invasiveness ability of cancer cells (25). We recently demonstrated that the co-presence of high-risk HPVs and EBV is linked to high/intermediate grade in different types of human carcinomas including $\operatorname{HN}(5,26,27)$. Thus, it is evident that the co-presence of high-risk HPVs and EBV in high-grade human carcinomas could suggest a possible cooperation between their oncoproteins; however, there are only few studies regarding the co-presence of high-risk HPVs and EBV in the ME region focusing only on NPCs.

Therefore, in this investigation, we assessed the presence of high-risk HPVs and EBV and their association with tumor phenotype in human $\mathrm{HN}$ cancer samples from Syria. Our study pointed out that high-risk HPVs and EBV are present in 43.7 and $51.2 \%$ of our samples, respectively, while coincidence of these oncoviruses is $32.2 \%$. More significantly, we noted that the co-incidence of these oncoviruses is associated with high/intermediate-grade squamous cell carcinomas in the majority of positive cases.

\section{MATERIALS AND METHODS High-Risk HPV and EBV Detection}

Eighty formalin-fixed paraffin-embedded blocks of HN cancer (57 larynx, 19 lower lip, 3 upper lip, and 1 nasopharynx) from Syrian patients, 73 males and 7 females, with an average age of 54.51 years were used. The samples were obtained from the Pathology Department, Faculty of Medicine of Aleppo University, Syria. Tissue blocks and data used in this report were approved, in March 22, 2009, by the Ethics Committee of the Faculty of Medicine of Aleppo University, \# 2009-007, Aleppo, Syria. One hundred nanograms of DNA was extracted from each sample using Qiagen GmbH kit (Hilden, Germany). These samples were analyzed for high-risk HPVs and EBV by PCR using primers for E6/E7 genes of high-risk HPV types (16, $18,31,33,35,45,51,52$, and 58 ) in addition to primers for LMP1 and EBNA1 genes of EBV; meanwhile, primers for the GAPDH gene were utilized as an internal control $(26,28)$. This analysis was achieved as illustrated earlier by our group $(5,26,28)$.

\section{Tissue Microarray}

Tissue microarray (TMA) building was realized as elucidated previously by our group $(28,29)$. Briefly, HN cancer samples were inserted into a virgin paraffin TMA block using a nonautomated tissue arrayer (Beecher Instruments, Silver Spring, MD) irrespective of pathological staging information. Three TMA cores of $1.0 \mathrm{~mm}$ in diameter were sampled from a cohort of 80 block tissue samples of Syrian HN cancer patients. Afterwards, to verify the histological diagnosis, $4-\mu \mathrm{m}$ sections were cut and stained with hematoxylin and eosin (H\&E). Then, slides of the completed blocks were used for immunohistochemistry assay.

\section{Immunohistochemistry}

Immunohistochemical (IHC) procedures examining the expression patterns of E6 and LMP1, of HPV and EBV, were done using standard practices. Briefly, slides were deparaffinized in graded alcohol, rehydrated, and boiled in $10 \mathrm{mM}$ citrate buffer ( $\mathrm{pH}$ 6.0) for antigen retrieval. Then, TMA slides were incubated for $35 \mathrm{~min}$ at $37^{\circ} \mathrm{C}$ with primary monoclonal and polyclonal antibodies for E6 of HPV and LMP1 of EBV (clones 1-4 and clone C1P5 from Dako and Calbiochem, Canada, respectively) using an automated immunostainer (Ventana Medical System, Tuscon, AZ). Afterwards, staining procedures were achieved according to the manufacturer's recommendations as slides were counterstained with hematoxylin prior to mounting. Negative controls were achieved by omitting primary antibody for E6 and LMP1. Following immunohistochemistry, two independent observers examined all TMA slides. The tumors were considered positive for E6 and LMP1 oncoproteins if cancer cells exhibited positivity $\geq 1 \%$ at any intensity $(\geq 1+$, scale $0-3+)$.

All TMAs also contained various cores representing positive and negative controls (e.g., cervical carcinoma and lymphatic tissues served as positive controls for HPV and EBV stains, respectively; normal $\mathrm{HN}$ tissues and epithelium were used as negative controls).

\section{Statistical Analysis}

Statistical assessments were achieved using IBM SPSS Statistics (version 22; SPSS Inc., Chicago, IL, USA) and R. Data were analyzed as non-parametric files. We used $\chi^{2}$-test with Yates correction to explore the significance of the association between tumor grade and the co-incidence of high-risk HPVs and EBV.

\section{RESULTS}

In order to classify the presence of high-risk HPVs and EBV in human HN cancer tissues in the ME region, we explored the 
TABLE 1 | High-risk HPVs and EBV detection in human head and neck cancers.

\begin{tabular}{lccc}
\hline Number of samples & HPVs+ & EBV + & HPVs+/EBV+ \\
\hline Positive cases & $35 / 80$ & $41 / 80$ & $25 / 80$ \\
$(\%)^{\# \#}$ & $(43.7)$ & $(51.2)$ & $(31.2)$
\end{tabular}

The presence of HPVs and EBV was found in 35 (43.7\%) and 41 (51.2\%) of the 80 cancer samples, respectively, while we observed that 25 (31.2\%) of cancer cases are positive for both high-risk HPVs and EBV. The presence of these oncoviruses was confirmed by PCR and IHC using specific primers for E6/E7 and LMP1 as well as EBNA1 genes of high-risk $H P V$ s and EBV, in addition to monoclonal antibodies for E6 and LMP1, as illustrated in the Materials and Methods section.

\# The total number of samples examined in this study is 80 .

\#\# These two methodologies, PCR and IHC, were used to detect the presences of high-risk $H P V$ s and EBV.

TABLE 2 | Presence of HPV types 16, 18, 31, 33, 35, 45, 51, 52, and 58 in human $\mathrm{HN}$ cancer.

\begin{tabular}{lccccccccc}
\hline \multirow{2}{*}{ No. of cases } & \multicolumn{8}{c}{ High-risk HPVs } \\
\cline { 2 - 10 } & $\mathbf{1 6}$ & $\mathbf{1 8}$ & $\mathbf{3 1}$ & $\mathbf{3 3}$ & $\mathbf{3 5}$ & $\mathbf{4 5}$ & $\mathbf{5 1}$ & $\mathbf{5 2}$ & $\mathbf{5 8}$ \\
\hline 80 & $31 / 80$ & $28 / 80$ & $13 / 80$ & $34 / 80$ & $18 / 80$ & $25 / 80$ & $15 / 80$ & $22 / 80$ & $20 / 80$ \\
\hline
\end{tabular}

We note that HPV types 33, 16, 18, and 45 are the most common in HN cancer in the Syrian population.

incidence of high-risk HPV types $16,18,31,33,35,45,51,52$, and 58 in a cohort of $80 \mathrm{HN}$ cancer specimens from the Syrian population by PCR analysis, using specific primers for E6/E7 and LMP1 as well as EBNA1 genes of HPVs and EBV, respectively $(5,26,28)$. Our data revealed that $35(43.7 \%)$ and $41(51.2 \%)$ of the 80 cancer samples are positive for high-risk HPVs and EBV, respectively (Table 1), and all of HPVs-positive specimens are co-infected with more than one HPV type. Regarding high-risk HPVs genotyping in these samples, our results pointed out that the most prevalent high-risk HPVs among the positive samples are types $33(34 / 80), 16(31 / 80), 18(28 / 80), 45(25 / 80), 52(22 / 80)$, $58(21 / 80), 35(18 / 80), 51(15 / 80)$, and $31(13 / 80)$, as shown in Table 2.

Next, we investigated the co-presence of high-risk HPVs and EBV in our HN cancer samples by IHC and PCR analysis using monoclonal antibodies, for E6 and LMP1, as well as specific primers for these oncoproteins/genes, respectively; we found that $25(31.2 \%)$ of the 80 cancer cases are positive for both high-risk HPVs and EBV with $P<0.001$ (Table 1). Furthermore, we examined the relation between the co-presence of these oncoviruses and tumor grade in these samples. Our data revealed that the co-expression of E6 and LMP1 oncoproteins of high-risk HPVs and EBV, respectively, in the majority of cases (88\%) is associated with high/intermediate (G3/G2)-grade invasive carcinoma form in comparison with high-risk HPVs+ or EBV+ alone cases or HPVs/EBV-negative cases, which are $4 / 10$ (40\%), 5/16 (31.2\%), and 3/29 (10.2\%) with $P=0.00328$, 0.00018 , and $<0.001$, respectively (Table 3 and Figures 1, 2), while it is important to highlight that cancer phenotype in the $\mathrm{HPV}^{+} / \mathrm{EBV}^{+}$was not linked to a specific HPV type since all our positive cases were infected with more than one type of highrisk HPVs. Finally, normal HN tissues and epithelial cells, which
TABLE 3 | High-risk HPVs and EBV status in relation to tumor grade in HN cancer samples.

\begin{tabular}{lcccc}
\hline $\begin{array}{l}\text { EBV/HPVs } \\
\text { status }\end{array}$ & $\begin{array}{c}\mathrm{EBV}^{+} / \mathrm{HPVs}^{+} \\
(\%)\end{array}$ & $\begin{array}{c}\mathrm{EBV}^{+} / \mathbf{H P V s}^{-} \\
(\%)\end{array}$ & $\begin{array}{c}\mathbf{E B V}^{-} / \mathbf{H P V S}^{+} \\
(\%)\end{array}$ & $\begin{array}{c}\mathbf{E B V}^{-} / \mathbf{H P V}^{-} \\
(\%)\end{array}$ \\
\hline TUMOR GRADE & & & & \\
High & $5(20.0)$ & $1(10.0)$ & $2(12.5)$ & $1(3.4)$ \\
Intermediate & $17(68.0)$ & $3(30.0)$ & $3(18.7)$ & $2(6.8)$ \\
Low & $3(12.0)$ & $6(60.0)$ & $11(68.7)$ & $26(89.6)$ \\
Number of & $25(31.2)$ & $10(12.5)$ & $16(20.0)$ & $29(36.2)$ \\
samples & & & &
\end{tabular}

We notice that $88 \%$ of HPVs- and EBV-positive cases are high/intermediate-grade carcinomas in comparison with $E B V^{+} / \mathrm{HPV}^{-}, E B V^{-} / \mathrm{HPV}^{+}$, and $E B V^{-} / \mathrm{HPV}^{-}$, which are $40,31.2$, and $10.2 \%$ with a P-value of $0.00328,0.00018$, and $<0.001$, respectively. \#The total number of samples examined in this study is 80 .

Values inside parentheses denote percentage.

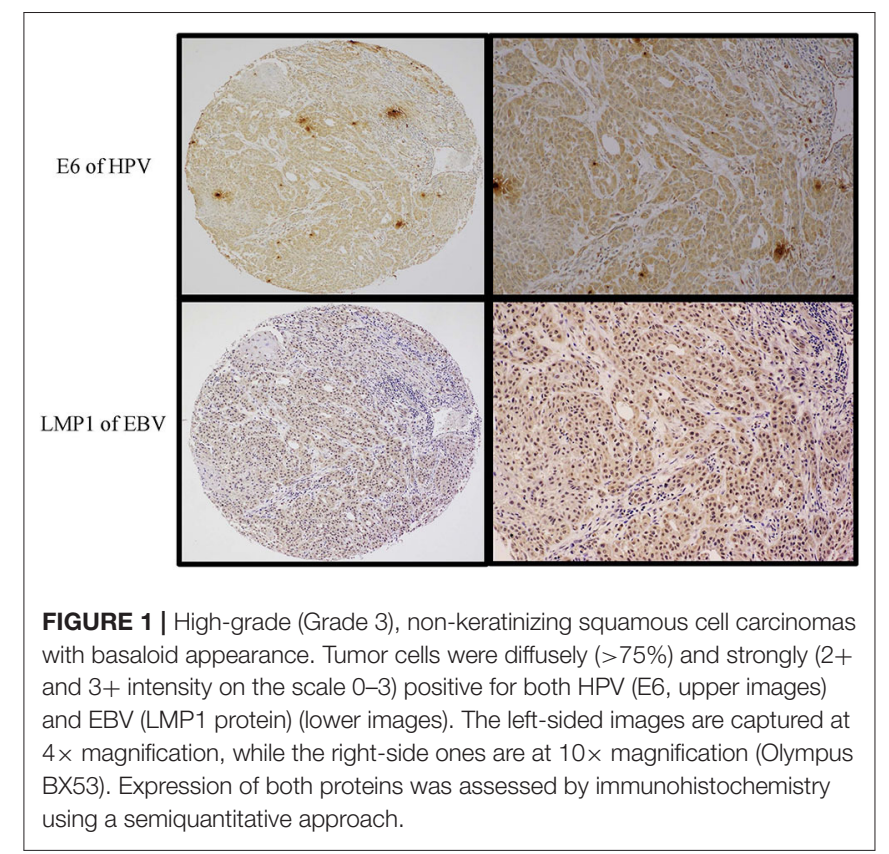

served as controls, were shown to be negative for both high-risk HPVs as well as EBV.

\section{DISCUSSION}

In this investigation, we explored, for the first time, the incidence/co-incidence of high-risk HPVs and EBV in human $\mathrm{HN}$ cancer and the association of their co-presence with tumor grade in Syria, which can also be considered the first study of this type in the ME region. We report that high-risk HPVs and EBV are present in 43.7 and $51.2 \%$, respectively, in our Syrian samples, and the most frequent HPV types in HN cancer in Syria are $33,16,18,45,52,58,35,51$, and 31 , correspondingly. Meanwhile, our data pointed out that $31.2 \%$ of the samples are positive for both high-risk HPVs and EBV. More significantly, we report that the co-presence of these oncoviruses is associated with high/intermediate tumor grade in $88 \%$ of the samples in 


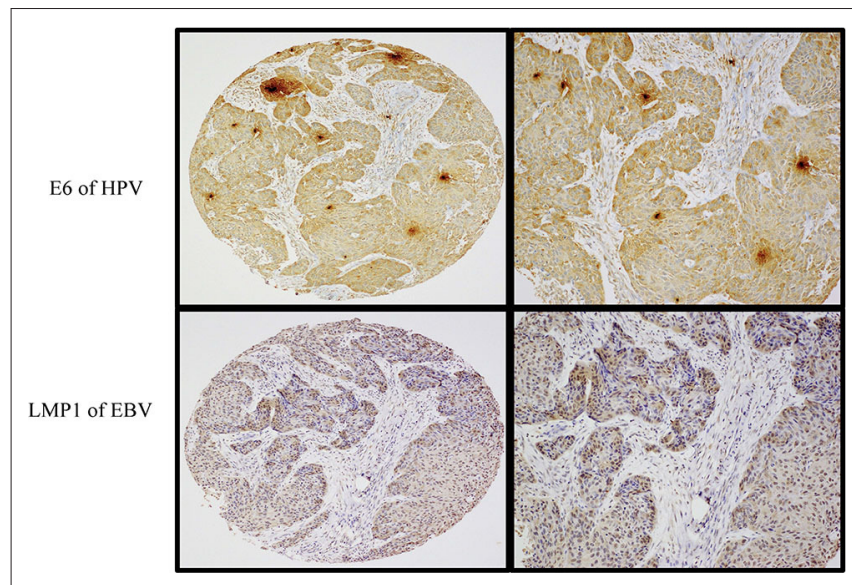

FIGURE 2 | A case of moderately differentiated (Grade 2) squamous cell carcinoma exhibiting co-expression of E6 (upper images) and LMP1 (lower images) oncoproteins of HPV and EBV, respectively. Left-sided images are captured at $4 \times$ magnification, while the right-sided ones are at $10 \times$ magnification (Olympus BX53). Note that the expression of E6 protein was observed in $>90 \%$ of cancer cells while LMP1 protein was expressed in $\sim 70 \%$ of cancer cells. Expression of both oncoproteins was assessed by immunohistochemistry using a semiquantitative approach.

comparison to HPVs or EBV-positive alone and HPVs/EBVnegative samples. Regarding the most common HPV types in the Syrian population, the present data concur with our previous studies on HPVs in different types of human carcinomas including cervical and breast in Syria where we found that HPV type 33 is the most frequent in these cancer tissues. In this context, HPV type 33 was reported to be the most common in breast cancer in Turkey (30). Herein, it is important to highlight that the Syrian samples were collected from Aleppo province, which is located in the northern part of the country bordering Turkey. Accordingly, our data confirm that specific types of highrisk HPV infection, in human cancers, are related to certain geographic locations, as it was demonstrated by a large number of investigations worldwide (7, 31-36).

Concerning the co-presence of HPVs and EBV in HN cancer in the ME region, Tatli Dogan et al. (37) published a study regarding the incidence of HPVs and EBV in NPCs in Turkey, they found that 72 of their 82 samples are positive for EBV and only one case revealed positive for HPVs; meanwhile, they reported that the highest rate of EBV positivity correspond with undifferentiated NPCs. However, and in agreement with our investigation, one report from North Africa assessed the presence and co-presence of high-risk HPVs and EBV in 70 cases of NPCs from the Moroccan population (38). Their study revealed that 24 of the samples are positive for high-risk HPVs, and the most frequent HPV types are $31,59,16,18,33$, and 35 . They found that all their cancer cases are positive for EBV. Consequently, 24 (34\%) Moroccan samples were positive for both high-risk HPVs and EBV, which are in their majority NPCs grade III and II. It is important to highlight that the Turkish and Moroccan studies in addition to another investigation from Iran with only 20 cancer cases (39) focused only on the co-presence of HPV and EBV in NPCs; therefore, our investigation can be considered the first study regarding the co-presence of these oncoviruses in $\mathrm{HN}$ cancer in the ME region since our samples include tissues from several HN locations.

On the other hand, in 2012, Jalouli et al. (40) examined the incidence and co-incidence of high-risk HPVs and EBV in 155 oral squamous cell carcinomas (OSCCs) from eight different countries from Europe, Asia, Africa, and North America with a limited number of cases $\sim 20$ cancer cases from each country including Sudan and Yemen from the ME region. They found that 35 and $55 \%$ of the samples are positive for HPVs and EBV, respectively. They reported that HPVs and EBV are co-present in $21 \%$ of all OSCCs. However, no clear conclusions can be drawn from this study due to the limited number of cancer cases from participant countries. Meanwhile, there are two recently published investigations from Europe regarding the presence of HPVs and EBV in human oral cancer; one from Poland showed that HPVs and EBV are co-present in $34.1 \%$ of cancer cases in comparison with HPV and EBV infections alone, which are 28.1 and $54.7 \%$, respectively (23). In the second study from Finland, the authors reported that the co-incidence of HPV and EBV is $14 \%$ in the population of Finland (41). In comparison, our study focused on the presence/co-presence of HPVs and EBV in HN cancer in Syria with an acceptable number of samples, which allowed us to make an adequate conclusion about these oncoviruses in $\mathrm{HN}$ cancer in this country, revealing that $31.2 \%$ of the samples are $\mathrm{HPVs}^{+} / \mathrm{EBV}^{+}$, which is comparable with the study published from Poland.

The co-presence of high-risk HPVs and EBV and their association with tumor phenotype in $\mathrm{HN}$ cancer is clearly demonstrated in our present study regardless of HPV type since all our HPV/EBV-positive cases are infected with more than one HPV virus strain. Our findings are in agreement with several investigations worldwide, including three from our group in addition to the Turkish and Moroccan studies; data of these reports pointed out that the co-presence of HPVs and EBV is associated with high-grade carcinomas in addition to positive axillary lymph nodes (5, 23, 25-27, 42, 43). Indeed, it has been reported that prevalence of poorly differentiated tumors is four times more frequent in HPV/EBV co-infection in comparison with EBV or HPV infection alone in oral cancer samples from Poland (23); in addition, the study pointed out that there is a significant correlation between tumor dimensions in co-infected patients compared with single infection. However, a recent investigation in NPCs reported that 5-year overall survival is significantly higher in HPV/EBV-positive patients in comparison with HPV/EBVnegative ones (41). Well, this could be due to radiation sensitivity as demonstrated by several investigations. Actually, earlier studies in HPV-positive cases of HNSCC found that the virus takes control of the cellular machinery for DNA repair, altering cell cycle distribution and causing hypoxia during radiation treatment $(44,45)$. On the other hand, numerous studies on the alteration of radiation response by EBV reported that LMP-1 blocks DNA repair by suppressing the phosphorylation and activity of DNA-dependent protein kinase, a key enzyme of non-homologous end-joining pathway in NPCs, and by repressing ATM, which ultimately modulates resistance of ionizing radiation-induced apoptotic cell death (46). 
Apropos the mechanism of HPVs and EBV interaction, based on the fact that high-risk HPVs and EBV oncoproteins share different downstream pathways, we assumed that oncoproteins (E5, E6/E7, LMP1, and EBNA1) of these oncoviruses can cooperate in the initiation and/or progression of several types of human carcinomas where the EMT event can play a crucial role in this procedure (47). Indeed, earlier investigations showed that E5 and E6/E7 oncoproteins of high-risk HPVs can enhance cell invasion and cancer progression via the induction of EMT in several types of human cancers including cervical and oral as well as NPCs (48-53). On the other hand, it has been reported by several investigations that LMP1, LMP2A, EBNA3C, and EBNA1 oncoproteins of EBV can enhance cancer progression via the modulation of EMT in human carcinomas including NPCs $(20,53-56)$. Meanwhile, our preliminary data showed that E6/E7 of HPV type 16 can cooperate with LMP1 of EBV to enhance EMT progression and consequently cell motility via the activation (phosphorylation) of Erk1/Erk 2 and $\beta$ catenin (in preparation). Nevertheless, further studies are needed to elucidate the complete pathogenesis and role of the coincidence of high-risk HPVs and EBV in human carcinomas including $\mathrm{HN}$, especially since $\mathrm{HPV}$ and $\mathrm{EBV}$ vaccines are currently available and under clinical trial, respectively (5759). This is a key step, which could possibly limit HPV and EBV infection and their associated cancers including $\mathrm{HN}$ malignancy initiation and development to a metastatic form, thus diminishing cancer-related mortalities especially in developing countries where oncoviruses-associated cancers are still considered major causes of death among both males and females in these countries.

Lastly, with regard to the number of specimens that we were able to amass from Aleppo, Syria, it is essential to confirm our data using a larger number of samples from different areas in this

\section{REFERENCES}

1. Daraei P, Moore CE. Racial disparity among the head and neck cancer population. J Cancer Educ. (2015) 30:546-51. doi: 10.1007/s13187-014-0 753-4

2. Ferlay J, Soerjomataram I, Dikshit R, Eser S, Mathers C, Rebelo M, et al. Cancer incidence and mortality worldwide: sources, methods and major patterns in GLOBOCAN 2012. Int J Cancer. (2015) 136:E359-86. doi: $10.1002 /$ ijc. 29210

3. Chaturvedi AK, Anderson WF, Lortet-Tieulent J, Curado MP, Ferlay J, Franceschi S, et al. Worldwide trends in incidence rates for oral cavity and oropharyngeal cancers. J Clin Oncol. (2013) 31:4550-9. doi: 10.1200/JCO.2013.50.3870

4. Al Moustafa A, Yasmeen A, Ghabreau L, Mohamed AH, Achkhar A. Brain metastases progression of breast cancer, breast cancer - carcinogenesis, cell growth and signalling pathways. In: Gunduz M, editor. London, UK: IntechOpen (2011).

5. Al-Thawadi H, Ghabreau L, Aboulkassim T, Yasmeen A, Vranic S, Batist G, et al. Co-Incidence of Epstein-Barr virus and high-risk human papillomaviruses in cervical cancer of Syrian women. Front Oncol. (2018) 8:250. doi: $10.3389 /$ fonc. 2018.00250

6. de Martel C, Ferlay J, Franceschi S, Vignat J, Bray F, Forman D, et al. Global burden of cancers attributable to infections in 2008: a review and synthetic analysis. Lancet Oncol. (2012) 13:607-15. doi: 10.1016/S1470-2045(12)70137-7 country and in combination with numerous investigations from the ME in general.

\section{DATA AVAILABILITY STATEMENT}

All datasets generated for this study are included in the article/supplementary material.

\section{ETHICS STATEMENT}

The studies involving human participants were reviewed and approved by Ethics Committee of the Faculty of Medicine of Aleppo University, \# 2009-007. Written informed consent for participation was not required for this study in accordance with the national legislation and the institutional requirements.

\section{AUTHOR CONTRIBUTIONS}

A-EA, SV, and HA-T conceived the study. LG provided the samples. IG, LG, SV, MM, AY, HA-T, and A-EA analyzed the data. All authors wrote and approved the final version of the manuscript. All authors contributed to the article and approved the submitted version.

\section{FUNDING}

This work was supported by Qatar University grants \# QUHI-CMED-19/20-1 and GCC-2017-002 QU/KU.

\section{ACKNOWLEDGMENTS}

The authors would like to thank Mrs. A. Kassab for her critical reading of the manuscript.

7. Al Moustafa AE, Al-Awadhi R, Missaoui N, Adam I, Durusoy R, Ghabreau L, et al. Human papillomaviruses-related cancers. Presence and prevention strategies in the middle east and north African regions. Hum Vaccin Immunother. (2014) 10:1812-21. doi: 10.4161/hv. 28742

8. Al Moustafa AE, Cyprian FS, Al-Antary N, Yasmeen A. High-risk human papillomaviruses and Epstein-Barr virus presence and crosstalk in human oral carcinogenesis. In: Al Moustafa AE, editor. Development of Oral Cancer: Risk Factors and Prevention Strategies. Cham: Springer International Publishing (2017). p. 83-94.

9. de Sanjosé S, Serrano B, Tous S, Alejo M, Lloveras B, Quirós B, et al. Burden of Human Papillomavirus (HPV)-related cancers attributable to HPVs 6/11/16/18/31/33/45/52 and 58. JNCI Cancer Spectrum. (2019) 2:pky045. doi: 10.1093/jncics/pky045

10. Graflund, M. SB, Sigurdardóttir S, Karlsson M. HPV-DNA, vascular space invasion, and their impact on the clinical outcome in earlystage cervical carcinomas. Int J Gynecol Cancer. (2004) 14:896-902. doi: 10.1111/j.1048-891X.2004.014527.x

11. Zuna R, Allen RA, Moore WE, Mattu R, Dunn ST. Comparison of human papillomavirus genotypes in high-grade squamous intraepithelial lesions and invasive cervical carcinoma: evidence for differences in biologic potential of precursor lesions. Mod Pathol. (2004) 17:1314-22. doi: 10.1038/modpathol.3800223

12. Umudum H, Rezanko T, Dag F, Dogruluk T. Human papillomavirus genome detection by in situ hybridization in fine-needle aspirates of metastatic lesions 
from head and neck squamous cell carcinomas. Cancer. (2005) 105:171-7. doi: $10.1002 /$ cncr.21027

13. Niedobitek G, Meru N, Delecluse HJ. Epstein-Barr virus infection and human malignancies. Int $J$ Exp Pathol. (2001) 82:149-70. doi: 10.1046/j.1365-2613.2001.iep0082-0149-x

14. Middeldorp JM, Brink AA, van den Brule AJ, Meijer CJ. Pathogenic roles for Epstein-Barr virus (EBV) gene products in EBV-associated proliferative disorders. Crit Rev Oncol Hematol. (2003) 45, 1-36. doi: 10.1016/S1040-8428(02)00078-1

15. Young LS, Rickinson AB. Epstein-Barr virus: 40 years on. Nat Rev Cancer. (2004) 4:757-68. doi: 10.1038/nrc1452

16. Murata T, Tsurumi T. Switching of EBV cycles between latent and lytic states. Rev Med Virol. (2014) 24:142-53. doi: 10.1002/rmv.1780

17. Elgui de Oliveira D, Müller-Coan BG, Pagano JS. Viral carcinogenesis Beyond malignant transformation: $\mathrm{EBV}$ in the progression of human cancers. Trends Microbiol. (2016) 24:649-64. doi: 10.1016/j.tim.2016.03.008

18. Gonzalez-Moles MA, Gutierrez J, Rodriguez MJ, Ruiz-Avila I, RodriguezArchilla A. Epstein-Barr Virus Latent Membrane Protein-1 (LMP-1) expression in oral squamous cell carcinoma. Laryngoscope. (2002) 112:482-7. doi: 10.1097/00005537-200203000-00014

19. Goldenberg D, Benoit NE, Begum S, Westra WH, Cohen Y, Koch WM, et al. Epstein-Barr Virus in head and neck cancer assessed by quantitative polymerase chain reaction. Laryngoscope. (2004) 114:1027-31. doi: 10.1097/00005537-200406000-00013

20. Gaur N, Gandhi J, Robertson ES, Verma SC, Kaul R. Epstein-Barr virus latent antigens EBNA3C and EBNA1 modulate epithelial to mesenchymal transition of cancer cells associated with tumor metastasis. Tumour Biol. (2015) 36:3051-60. doi: 10.1007/s13277-014-2941-6

21. Zuo LL, Zhang J, Liu LZ, Zhou Q, Du SJ, Xin SY, et al. Cadherin 6 is activated by Epstein-Barr virus LMP1 to mediate EMT and metastasis as an interplay node of multiple pathways in nasopharyngeal carcinoma. Oncogenesis. (2017) 6:402-402. doi: 10.1038/s41389-017-0005-7

22. Deng Z, Uehara T, Maeda H, Hasegawa M, Matayoshi S, Kiyuna A, et al. Epstein-Barr virus and human papillomavirus infections and genotype distribution in head and neck cancers. PLoS ONE. (2014) 9:e113702. doi: 10.1371/journal.pone.0113702

23. Drop B, Strycharz-Dudziak M, Kliszczewska E, Polz-Dacewicz M. Coinfection with Epstein-Barr Virus (EBV), Human Papilloma Virus (HPV) and Polyoma $\mathrm{BK}$ Virus (BKPyV) in laryngeal, oropharyngeal and oral cavity cancer. Int $J$ Mol Sci. (2017) 18:2752. doi: 10.3390/ijms18122752

24. Huang WB, Chan JYW, Liu DL. Human papillomavirus and World Health Organization type III nasopharyngeal carcinoma: multicenter study from an endemic area in Southern China. Cancer. (2018) 124:530-6. doi: $10.1002 /$ cncr.31031

25. Jiang R, Ekshyyan O, Moore-Medlin T, Rong X, Nathan S, Gu X, et al. Association between human papilloma virus/Epstein-Barr virus coinfection and oral carcinogenesis. J Oral Pathol Med. (2015) 44:28-36. doi: $10.1111 /$ jop. 12221

26. Al Moustafa AE, Al-Antary N, Aboulkassim T, Akil N, Batist G, Yasmeen A. Co-prevalence of Epstein-Barr virus and high-risk human papillomaviruses in Syrian women with breast cancer. Hum Vaccin Immunother. (2016) 12:19369. doi: $10.1080 / 21645515.2016 .1139255$

27. Malki MI, Gupta I, Fernandes Q, Aboulkassimc T, Yasmeen A, Vranic S, et al. Co-presence of Epstein-Barr virus and high-risk human papillomaviruses in Syrian colorectal cancer samples. J Hum Vaccin Immunother. (2020). doi: 10.1080/21645515.2020.1726680. [Epub ahead of print].

28. Darnel AD, Wang D, Ghabreau L, Yasmeen A, Sami S, Akil N, et al. Correlation between the presence of high-risk human papillomaviruses and Id gene expression in Syrian women with cervical cancer. Clin Microbiol Infect. (2010) 16:262-6. doi: 10.1111/j.1469-0691.2009.02774.x

29. Akil N, Yasmeen A, Kassab A, Ghabreau L, Darnel AD, Al Moustafa AE. Highrisk human papillomavirus infections in breast cancer in Syrian women and their association with Id-1 expression: a tissue microarray study. Br J Cancer. (2008) 99:404-7. doi: 10.1038/sj.bjc.6604503

30. Gumus M, Yumuk PF, Salepci T, Aliustaoglu M, Dane F, Ekenel M, et al. HPV DNA frequency and subset analysis in human breast cancer patients' normal and tumoral tissue samples. J Exp Clin Cancer Res. (2006) $25,515-21$.
31. Abramowitz L, Jacquard A-C, Jaroud F, Haesebaert J, Siproudhis L, Pradat P, et al. Human papillomavirus genotype distribution in anal cancer in France: the EDiTH V study. Int J Cancer. (2011) 129:433-9. doi: 10.1002/ijc.25671

32. García Muentes GD, García Rodríguez LK, Burgos Galarraga RI, Almeida Carpio F, Ruiz Cabezas JC. Genotypes distribution of human papillomavirus in cervical samples of Ecuadorian women. Revista Brasileira de Epidemiologia. (2016) 19:160-6. doi: 10.1590/1980-5497201600010014

33. Li Z, Liu F, Cheng S, Shi L, Yan Z, Yang J, et al. Prevalence of HPV infection among 28,457 Chinese women in Yunnan Province, southwest China. Sci Rep. (2016) 6:21039. doi: 10.1038/srep21039

34. Wang L, Wang P, Ren Y, Du J, Jiang J, Jia X, et al. Prevalence of HighRisk Human Papillomavirus (HR-HPV) genotypes and multiple infections in cervical abnormalities from Northern Xinjiang, China. PLoS ONE. (2016) 11:e0160698. doi: 10.1371/journal.pone.0160698

35. Gheit T, Anantharaman D, Holzinger D, Alemany L, Tous S, Lucas E, et al. Role of mucosal high-risk human papillomavirus types in head and neck cancers in central India. Int J Cancer. (2017) 141:143-51. doi: $10.1002 /$ ijc. 30712

36. Tang Y, Zheng L, Yang S, Li B, Su H, Zhang LP. Epidemiology and genotype distribution of human papillomavirus (HPV) in Southwest China: a crosssectional five years study in non-vaccinated women. Virol J. (2017) 14:84. doi: 10.1186/s12985-017-0751-3

37. Tatli Dogan H, Kiliçarslan A, Dogan M, Süng,ü N, Güler Tezel G, Güler G. Retrospective analysis of oncogenic human papilloma virus and Epstein-Barr virus prevalence in Turkish nasopharyngeal cancer patients. Pathol Res Pract. (2016) 212:1021-6. doi: 10.1016/j.prp.2016.08.013

38. Laantri N, Attaleb M, Kandil M, Naji F, Mouttaki T, Dardari R, et al. Human papillomavirus detection in moroccan patients with nasopharyngeal carcinoma. Infect Agents Cancer. (2011) 6:3-3. doi: 10.1186/1750-9378-6-3

39. Mirzamani N, Salehian P, Farhadi M, Tehran EA. Detection of EBV and HPV in nasopharyngeal carcinoma by in situ hybridization. Exp Mol Pathol. (2006) 81:231-4. doi: 10.1016/j.yexmp.2006.04.006

40. Jalouli J, Jalouli MM, Sapkota D, Ibrahim SO, Larsson PA., Sand L. Human papilloma virus, herpes simplex virus and Epstein Barr virus in oral squamous cell carcinoma from eight different countries. Anticancer Res. (2012) 32:57180.

41. Ruuskanen M, Irjala H, Minn H, Vahlberg T, Randen-Brady R, Hagström J, et al. Epstein-Barr virus and human papillomaviruses as favorable prognostic factors in nasopharyngeal carcinoma: a nationwide study in Finland. Head Neck. (2019) 41:349-57. doi: 10.1002/hed.25450

42. Glenn WK, Heng B, Delprado W, Iacopetta B, Whitaker NJ, Lawson JS. Epstein-Barr virus, human papillomavirus and mouse mammary tumour virus as multiple viruses in breast cancer. PLoS ONE. (2012) 7:e48788-e48788. doi: 10.1371/journal.pone. 0048788

43. Broccolo F, Ciccarese G, Rossi A, Anselmi L, Drago F, Toniolo A. Human papillomavirus (HPV) and Epstein-Barr virus (EBV) in keratinizing versus non- keratinizing squamous cell carcinoma of the oropharynx. Infect Agents Cancer. (2018) 13:32. doi: 10.1186/s13027-018-0205-6

44. Weaver AN, Cooper TS, Rodriguez M, Trummell HQ, Bonner JA, Rosenthal EL, et al. DNA double strand break repair defect and sensitivity to poly ADPribose polymerase (PARP) inhibition in human papillomavirus 16-positive head and neck squamous cell carcinoma. Oncotarget. (2015) 6:26995-7007. doi: 10.18632 /oncotarget. 4863

45. Swick AD, Chatterjee A, De Costa A-MA, Kimple RJ. Modulation of therapeutic sensitivity by human papillomavirus. Radiother Oncol. (2015) 116:342-5. doi: 10.1016/j.radonc.2015.09.002

46. Rödel F, Martin D, Balermpas P, Wieland U, Winkelmann R, Riekmann T, et al. Modulation of radiation sensitivity and antitumor immunity by viral pathogenic factors: Implications for radio-immunotherapy. Biochim Biophys Acta Rev Cancer. (2019) 1871:126-37. doi: 10.1016/j.bbcan.2018.12.006

47. Cyprian FS, Al-Farsi HF, Vranic S, Akhtar S, Al Moustafa A-E. Epstein-Barr virus and human papillomaviruses interactions and their roles in the initiation of epithelial-mesenchymal transition and cancer progression. Front Oncol. (2018) 8:111. doi: 10.3389/fonc.2018.00111

48. Cheng Y-M, Chou C-Y, Hsu Y-C, Chen M-J, Wing L-YC. The role of human papillomavirus type $16 \mathrm{E} 6 / \mathrm{E} 7$ oncoproteins in cervical epithelialmesenchymal transition and carcinogenesis. Oncol Lett. (2012) 3:667-71. doi: $10.3892 / 01.2011 .512$ 
49. Chamulitrat W, Sattayakhom A, Herold-Mende C, Stremmel W. Human papillomavirus 16 E6/E7-immortalized human gingival keratinocytes with epithelial mesenchymal transition acquire increased expression of cIAP-1, Bclx and p27Kip1. Exp Dermatol. (2009) 18:1067-9. doi: 10.1111/j.1600-0625.2009.00888.x

50. Jung YS, Kato I, Kim HR. A novel function of HPV16-E6/E7 in epithelialmesenchymal transition. Biochem Biophys Res Commun. (2013) 435:339-44. doi: 10.1016/j.bbrc.2013.04.060

51. Hatakeyama H, Mizumachi T, Sakashita T, Kano S, Homma A, Fukuda S. Epithelial-mesenchymal transition in human papillomavirus-positive and negative oropharyngeal squamous cell carcinoma. Oncol Rep. (2014) 32:267379.

52. Wakisaka N, Yoshida S, Kondo S, Kita M, Sawada-Kitamura S, Endo K, et al. Induction of epithelial-mesenchymal transition and loss of podoplanin expression are associated with progression of lymph node metastases in human papillomavirus-related oropharyngeal carcinoma. Histopathology. (2015) 66:771-80. doi: 10.1111/his.12496

53. Chen X, Bode AM, Dong Z, Cao Y. The epithelial-mesenchymal transition (EMT) is regulated by oncoviruses in cancer. Faseb j. (2016) 30:3001-10. doi: 10.1096/fj.201600388R

54. Horikawa T, Yang J, Kondo S, Yoshizaki T, Joab I, Furukawa M, et al. Twist and Epithelial-mesenchymal transition are induced by the EBV oncoprotein latent membrane protein 1 and are associated with metastatic nasopharyngeal carcinoma. Cancer Research. (2007) 67:1970-8. doi: 10.1158/0008-5472.Can-06-3933

55. Horikawa T, Yoshizaki T, Kondo S, Furukawa M, Kaizaki Y, Pagano JS. Epstein-Barr Virus latent membrane protein 1 induces Snail and epithelial-mesenchymal transition in metastatic nasopharyngeal carcinoma Br J Cancer. (2011) 104:1160-7. doi: 10.1038/bjc.2011.38

56. Kong Q-L, Hu L-J, Cao J-Y, Huang Y-J, Xu L-H, Liang Y, et al. Epstein-Barr virus-encoded LMP2A induces an epithelial-mesenchymal transition and increases the number of side population stem-like cancer cells in nasopharyngeal carcinoma. PLoS Pathog. (2010) 6:e1000940. doi: 10.1371/journal.ppat.1000940

57. Lee LY, Garland SM. Human papillomavirus vaccination: the population impact. F1000Research. (2017) 6:866. doi: 10.12688/f1000research.10691.1

58. Luxembourg A, Moeller E. 9-Valent human papillomavirus vaccine: a review of the clinical development program. Expert Rev Vaccin. (2017) 16:1119-39. doi: 10.1080/14760584.2017.1383158

59. Rajčáni J, Bánáti F, Szenthe K, Szathmary S. The potential of currently unavailable herpes virus vaccines. Expert Rev Vaccin. (2018) 17:239-48. doi: 10.1080/14760584.2018.1425620

Conflict of Interest: The authors declare that the research was conducted in the absence of any commercial or financial relationships that could be construed as a potential conflict of interest.

Copyright (C) 2020 Gupta, Ghabreau, Al-Thawadi, Yasmeen, Vranic, Al Moustafa and Malki. This is an open-access article distributed under the terms of the Creative Commons Attribution License (CC BY). The use, distribution or reproduction in other forums is permitted, provided the original author(s) and the copyright owner(s) are credited and that the original publication in this journal is cited, in accordance with accepted academic practice. No use, distribution or reproduction is permitted which does not comply with these terms. 